\title{
Congenital Double Lip - A Psychological Stigma
}

Maj Devendra Srivastava ${ }^{1}$, Col A K Shreehari², Maj Raghavendra $\mathrm{M} \mathrm{H}^{3}$, Brig I D Roy ${ }^{4}$

Quick Response Code

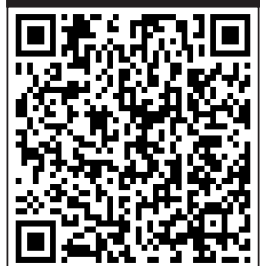

doi: $10.5866 / 2016.8 .10111$

${ }^{1}$ Graded Specialist (Periodontics),

21 Corps Dental Unit,

Armed Forces Medical College, Pune.

${ }^{2}$ Associate Professor,

Department of Dental Surgery, AFMC, Pune

${ }^{3}$ Graded Specialist (Periodontics),

3 Corps Dental Unit

Armed Forces Medical College, Pune.

${ }^{4}$ Associate Professor

Department of Dental Surgery

Armed Forces Medical College, Pune.

\section{Article Info:}

Received: April 10, 2016

Review Completed: May 11, 2016

Accepted: J une 13, 2016

Available Online: September, 2016 (www.nacd.in)

(C) NAD, 2016 - All rights reserved

\section{Email for correspondence:}

drdeven11@gmail.com

\begin{abstract}
:
Double lip is an infrequent rare lip anomaly usually involving the upper lip. The occurrence of double lip affects aesthetics especially when patient smiles but may also interfere with speech and mastication. Surgical treatments are mostly for cosmetic reasons and results are generally good and complications are rare. A case of congenital double lip which was treated surgically for cosmetic reason is reported.
\end{abstract}

Key words: Congenital double lip, management of double lip.

\section{INTRODUCTION}

Double lip is an infrequent rare lip anomaly usually involving the upper lip, which is most often congenital; however it could be acquired as a result of trauma. ${ }^{1}$ Typical appearance of double lip is seen when the lips are tensed during smiling. It consists of a fold of excess or redundant tissue on the mucosal side of thelip. A doublelip presents as a double vermilion with a transverse furrow between the two borders which appear when the orbicularis oris muscle contracts during a smile. During smiling, the lip is retracted and the mucosa is positioned over the maxillary teeth, resulting in a "Cupid's bow" appearance. The incidence of this anomaly is not known and it may be either isolated or in association with other congenital abnormalities. Treatment is by excision of the excess mucosa and sub-mucosal tissue. ${ }^{2}$ 


\section{CASE REPORT}

A 26-year-old male patient was referred to the Division of Periodontology, AFMC, Pune from the general OPD with the chief complaint of a painless swelling of the upper lip. Patient gave a history of presence of the swellings since childhood and there was no history of any trauma. On examination the swelling on theright side measured $1 \times 1.5 \mathrm{~cm}$, oblong in shapeand extended $0.5 \mathrm{~cm}$ onto the labial mucosa while the swelling on the left side measured $1 \times 1 \mathrm{~cm}$ and extended $0.4 \mathrm{~cm}$ onto the labial mucosa intraorally. Theswelling extended to cover one-third to half of the labial surface of the maxillary anteriors (Figure 1). The swellings were of normal mucosal color and were visible only when the lips were stretched or when the patient smiled. On pal pation the swellings on the upper lip were fibrous, mobile and non-fluctuant. As doublelip could be associated with blepharochalasis and non-toxic thyroid enlargement, the same was ruled out by a complete clinical examination.

A provisional diagnosis of congenital bilateral upper double lip was established, and surgical excision was suggested to the patient. Under local anesthesia (bilateral infraorbital nerve blocks), excess tissue was marked using methylene blue dye and the redundant labial mucosal mass was excised by two elliptical excisions, one on each half of the lip, and combined with a central Z-plasty to release the constricting band (Figure 2). Closure was by running 5/0 polyglactin 910 (Vicryl) suture (Figure 3). Postoperative recovery was uneventful and there were no signs of relapse after 3 month (Figure 4).

Histologic examination of the excised material revealed sections of soft tissue covered by stratified squamous epithelium with parakeratosis. Numerous minor salivary glands with moderate lymphocytic infiltration were present in the underlying connective tissue. No muscle fibers were present in the specimen.

An implant supported prosthesis using the early loading protocol was doneto rehabilitatethemissing left central incisor, being in an aesthetic zone (Figure 5). Patient is under regular follow up and there is no recurrence of the lesion after one year (Figure $6)$.

\section{DISCUSSION}

Double lip may be either a congenital abnormality or an acquired deformity. The congenital form usually involves the upper lip, but it may also affect the lower lip., ${ }^{3} 4$ It usually occurs as a redundant fold of tissue on the mucosal part of the lip. During the development of the mucosa, the upper lip consists of two transverse zones viz, an outer zone called the pars glabrosa, which is smooth and similar to the skin and the inner zone termed as the pars villosa, which is villous and similar to the oral mucosa. The Double lip devel ops during the second or third intrauterine month as a result of the persistence of the horizontal sulcus between the pars glabrosa and the pars villosa. ${ }^{5}$ The acquired form of double lip is probably a manifestation resulting due to 'sucking in' of the tissue between the teeth or maloccluded dentures. The acquired form of double lip may be secondary to trauma and oral habit, and may develop in association with Ascher's syndrome which consists of the triad of blepharochalasis, nontoxic thyroid enlargement and double lip. ${ }^{6}$

The differential diagnosis should include cheilitis glandularis, vascular tumors, lymphangioma, angioedema, meischer's syndrome, mucocele, salivary gland tumors, sarcoidosis, inflammatory fibrous hyperplasia and plasma cell cheilitis, urbach weithe disease and mucosal neuromas of multiple endocrine neoplasia syndrome. ${ }^{7}$

Treatment of double lip is indicated when the excess tissue interferes with mastication, speech or leads to habits such as sucking or biting of the redundant tissue or is of aesthetic concern. The condition is treated surgically with W-plasty or transverse elliptical incision to excise the hypertrophic mucosa. ${ }^{8}$ Other techniques used are triangular incision and electro surgical excision using el ectrocautery and more recently LASE R. ${ }^{9}$ In patients with a short central constriction band as in the reported case, the use of two elliptical incisions along with a vertical Z-plasty results in a pleasing appearance of the upper lip with a natural-looking tubercle. ${ }^{10}$ The cosmetic results are generally very good and aesthetically acceptable. The relapse and 


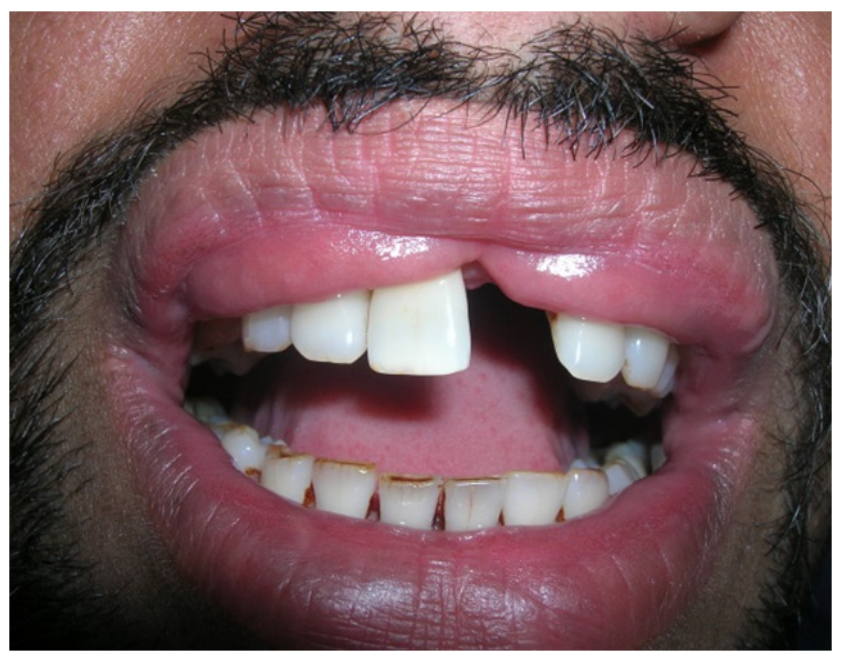

Figure 1: Double lip deformity when patient smiles.

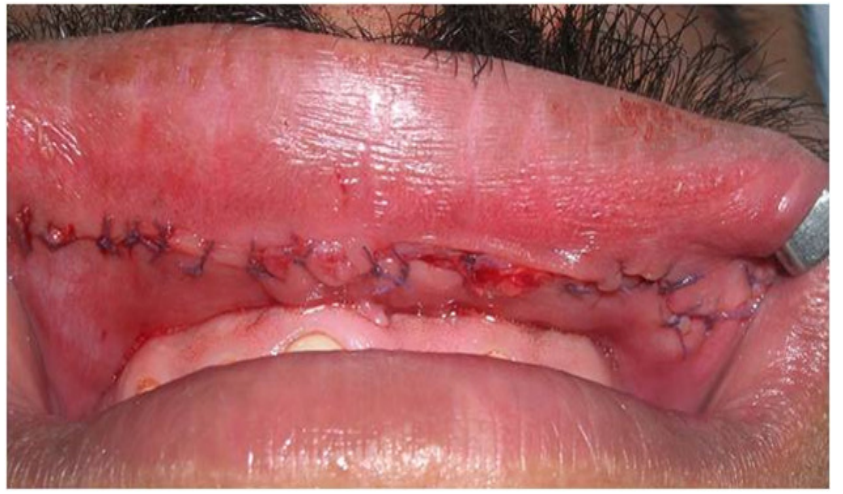

Figure 3: I mmediate Post-op after suturing

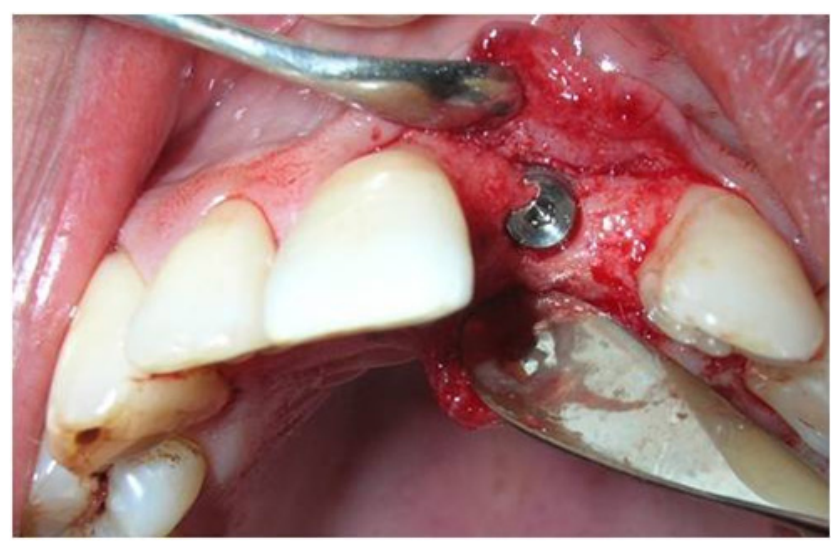

Figure 5: I mplant placed in missing left central incisor

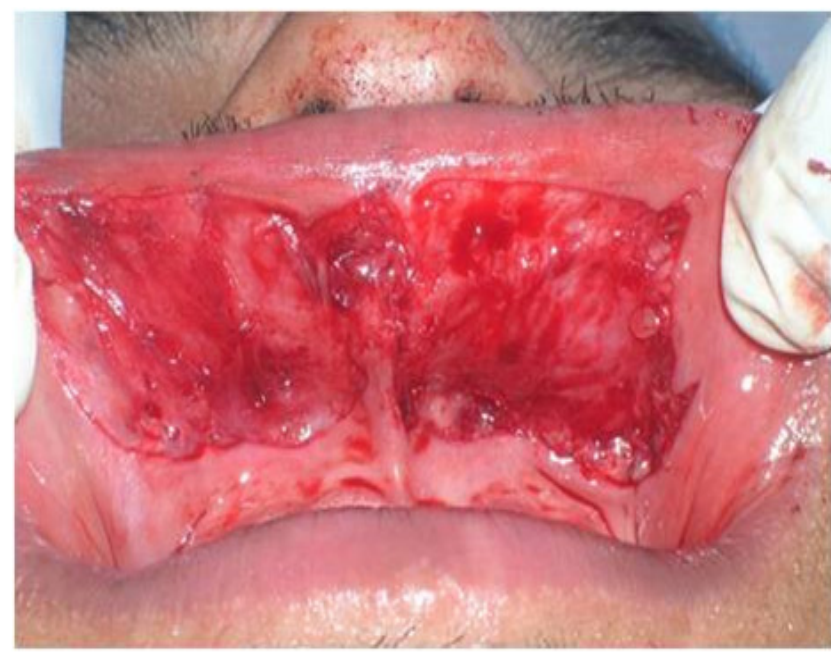

Figure 2: Excision after two elliptical incision and central zplasty

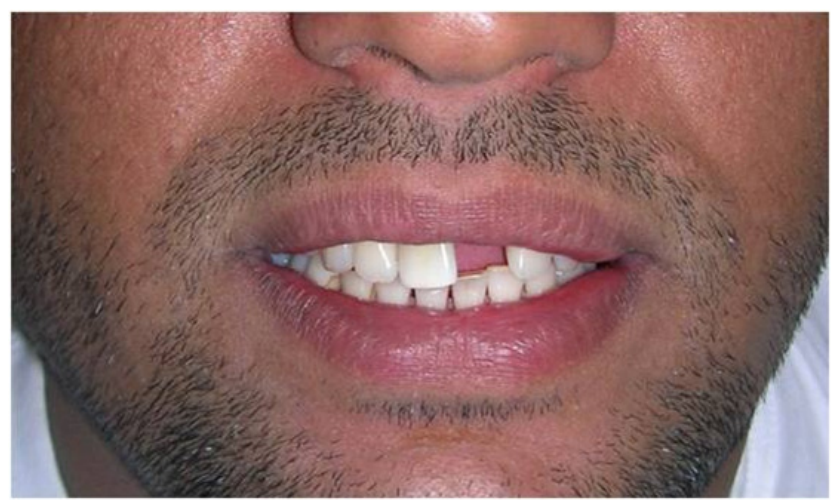

Figure 4: Post operative picture of the patient after 3 months.

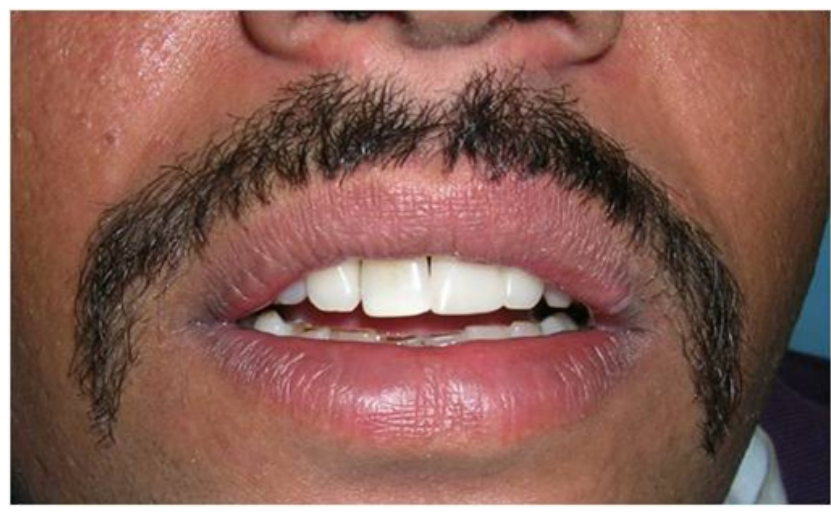

Figure 6: Post-operative picture after 1 year with rehabilitated missing left central incisor. 
complications such as glandular hypertrophy or mucocele are extremely rare.

\section{CONCLUSION}

Double lip is a rare oral anomaly. Careful diagnostic evaluation and follow up is critical in the management of these patients. Surgical treatment is indicated when the excess tissue interferes with mastication, speech or more commonly for esthetic reasons. Thesurgical results aregenerally very good and complications are extremely rare.

\section{REFERENCES}

1. Alkan A, Metin M. Maxillary double lip: report of two cases. J Oral Sci. 2001; 43:69-72.

2. Martins WD, Westphalen FH, Sandrin R, Campagnoli E. Congenital Maxillary Double lip: Review of literature and report of a case. J Can Dent Assoc 2004; 70:466-468.

3. Converse J M, Wood-Smith D, Macomber WB, Wang MKH. Reconstructive Plastic Surgery. 2nd ed. Philadelphia: Saunders; 1977 p.1543.
4. Reddy KA, Roa AK. Congenital double lip: a review of seven cases. Plast Reconstr Surg. 1989; 84:420-423.

5. Kara IG, Kara CO. Ascher syndrome. Otolaryngol Head Neck Surg. 2001; 124:236-237.

6. Santos PP, Alves PM, Freitas VS, Souza LB. Double lip surgical correction in Ascher's syndrome-diagnosis and treatment of a rare condition. Clinics 2008; 63:709-712.

7. Goyal S, Godhi S, Goyal S. Non syndromic congenital maxillary double lip- a rare case. J Oral Health Comm Dent 2008; 2:10-12.

8. Guerrero-Santos J , Altamirano J T. The use of W-plasty for the correction of double lip deformity. Plast Reconstr Surg. 1967; 39:478-481.

9. Beinhoff $U$, Piza-Katzer $\mathrm{H}$. Double lip in a patient with Ascher's syndrome. Eur J Plast Surg 1998; 21:370-373.

10. Eski M, Nisanci M, Aktas A, Sengezer M. Congenital double lip: review of 5 cases. BrJ Oral Maxillofac Surg 2007; 45:6870.

\section{Gain quick access to our journal online View our journal at www.nacd.in}

